\title{
One Dimensional Numerical Simulation of Aggradation-Degradation in a Channel Using Finite Difference Method Case Study Chashma Right Bank Canal (CRBC)
}

\author{
Muhammad Zain Bin Riaz*, Abdul Sattar Shakir and Muhammad Masood \\ Centre of Excellence in Water Resources Engineering, University of Engineering and Technology Lahore, Pakistan
}

\begin{abstract}
A one-dimensional MacCormack explicit finite difference model is developed for simulating hydraulics and bed changes in irrigation channels. The Saint-Venant equations describing unsteady flow in open channels and the continuity equation for the conservation of sediment mass are numerically solved. These equations are highly nonlinear and therefore do not have analytical solutions. For this purpose the MacCormack scheme is used. The scheme is second order accurate; it is a coupled solution as it is a two-step predictor corrector method. Model gives results in terms of bed level changes, flow depth and discharge provided physical boundaries of the system are valid for simulation time. Model execution and accuracy is very sensitive to time step and stability. The simulated results show a good agreement with previous studies in the downstream section, and can predict an average value of measured profile in the upstream section. The application of this model to Chashma Right Bank Canal in Pakistan and results of the model are compared with the published results gave very convincing result.
\end{abstract}

Keywords: Saint-Venant equation, Irrigation channel, Bed level change, MacCormack Scheme

\section{Introduction}

The design of hydraulic structures and water resources system, in the analysis of channel mechanics problems and in the development of channel control works is of vital importance in gradually varied unsteady flow in open channels described by solution of equations. Transport of sediment by flow and its scour or depositions are involved in many of these problems of rivers and canals. Even when the flows are steady, sediment transport phenomena are often time variant. Appropriate quantification of aggradation and/or degradation and variations in channel form of such channel still has been a subject of considerable research. From the viewpoint of improved planning and designing of various water development projects, a systematic study on the aggradation-degradation phenomenon of these channels of Pakistan is, therefore, of utmost importance.

To study the effect of the long term and short term bed level changes in alluvial channels with different flow conditions, a number of experimental had been conducted. Begin et al. [1] experimentally studied degradation of alluvial networks in response to lowering of the bed level. Soni et al. [2] conducted an experiment that covered a extensive range of flow and sediment loading conditions. They observed that after a long time, when the hydraulic conditions became compatible with the increased sediment load, the aggradation in downstream of the section of increased sediment supply was stopped. Yen et al. [3] found out that both the aggradation wave speed and the mean sediment transport velocity increase with the initial equilibrium bed slope and with decreasing loading ratio after performing a series of overloading experiments with uniform coarse sediment. To study the reversibility of an alternation aggradation-degradation process, a series of experiments were conducted by Yen et al. [4]. The results show that as standard deviation of sediment gradation increases the recovery rate decreases. MacCormack scheme was applied by Alam [5] to the study of aggradation-degradation in alluvial channels. Kassem and Chaudhry [6] developed a two dimensional numerical model to predict the time variation of bed deformation in alluvial channel bends. In this model, Beam and Warming alternating direction implicit scheme are used to solve the depth-averaged unsteady water flow equations along with the sediment continuity equation. Deng and Li [7] used the one dimensional unsteady flow and sediment transport model to study the river channel equilibrium profile. For sediment transport, erosion and deposition in straight channels and rivers some of the widely used one dimensional models are MIKE11 (DHI [8] and HEC-6 (USACE). Current study uses the explicit finite difference method to determine the rate and extent of bed level-changes due to transient conditions of flow and sediment (routing of sediment laden water). The finite difference explicit method of MacCormack is used to numerically solve the continuity and momentum equations along with the sediment mass balance equation.

The present work is aimed at investigating more closely where relatively rapid changes in both fluid and sediment discharge are imposed at the upstream boundary, with coupled solution through MacCornaack.

\section{Computational Procedures}

Flow computations, and sediment routing are two parts in each step of the simulation method. Firstly flow computation is executed then sediment routing is executed to compute the quantity of channel bed variations. (Figure 1) shows the computational flow.

\section{Numerical simulations}

The effective application of a model basically depends on the

*Corresponding author: Muhammad Zain Bin Riaz, Centre of Excellence in Water Resources Engineering, University of Engineering and Technology Lahore, Pakistan, Tel: +92 42 99029227; E-mail: zainie38@yahoo.com

Received March 27, 2017; Accepted September 30, 2017; Published October 20, 2017

Citation: Riaz MZB, Shakir AS, Masood M (2017) One Dimensional Numerical Simulation of Aggradation-Degradation in a Channel Using Finite Difference Method Case Study Chashma Right Bank Canal (CRBC). Fluid Mech Open Acc 4: 178. doi: 10.4172/2476-2296.1000178

Copyright: ( 2017 Riaz MZB, et al. This is an open-access article distributed unde the terms of the Creative Commons Attribution License, which permits unrestricted use, distribution, and reproduction in any medium, provided the original author and source are credited. 


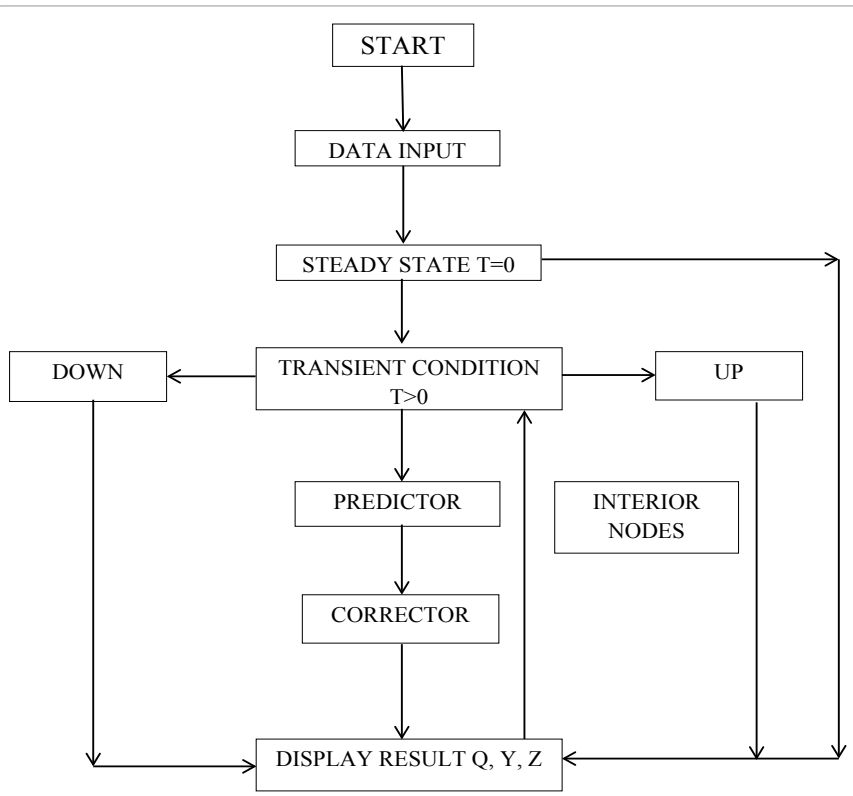

Figure 1: Computational flow chart.

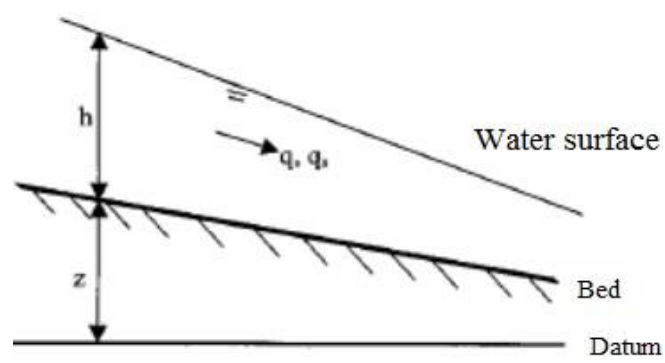

Figure 2: Definition sketch of variable.

accurate path to develop the model for a certain problem. The assumptions used in the numerical model development to simplify a phenomenon are sometimes critical to the extent of their validity. From the basic equations describing the problem, a model is developed considering all the limitations.

\section{Governing equations}

The one-dimensional partial differential equations describing unsteady flow in a channel with movable bed (Figure 2) are given by:

1) Continuity equation for water

$\frac{\partial \mathrm{h}}{\partial \mathrm{t}}+\frac{\partial \mathrm{q}}{\partial \mathrm{x}}=0$

2) Momentum equation for water

$$
\frac{\partial \mathrm{q}}{\partial \mathrm{t}}+\frac{\partial}{\partial \mathrm{x}}\left(\frac{\mathrm{q}^{2}}{\mathrm{~h}}+\frac{1}{2} \mathrm{gh}^{2}\right)+\mathrm{gh} \frac{\partial \mathrm{z}}{\partial \mathrm{x}}+\mathrm{ghs}_{\mathrm{f}}=0
$$

3) Continuity equation for sediment

$$
\frac{\partial}{\partial t}\left[(1-p) z+\frac{q_{s} h}{q}\right]+\frac{\partial q_{s}}{\partial x}=0
$$

Terms used in these equations are defined as, $\mathrm{q} \quad=$ Water discharge per unit width

$\mathrm{h}=$ Depth of flow

$\mathrm{q}_{\mathrm{s}} \quad=$ Unit sediment discharge

$\mathrm{g}=$ Acceleration due to gravity

$\mathrm{S}_{\mathrm{f}} \quad=$ Friction slope

$\mathrm{t} \quad=$ Time

$\mathrm{p} \quad=$ Porosity of bed layer

$\mathrm{x}=$ Longitudinal distance along the channel

$\mathrm{t}=$ Time

$\mathrm{p}=$ Porosity of bed layer.

The friction slope, $\mathrm{S}_{\mathrm{f}}$ is calculated using the Manning equation (SI unit):

$S_{f}=\frac{q^{2} n^{2}}{h^{3.333}}$

Where, $\mathrm{n}=$ Manning roughness coefficient.

The sediment discharge is predicted by an empirical function of the flow velocity:

$$
\mathrm{q}_{\mathrm{s}}=\mathrm{a}\left(\frac{\mathrm{q}}{\mathrm{h}}\right)^{\mathrm{b}}
$$

Where, a, b are empirical constants to be adjusted. Values of $a, b$ depend upon sediment properties and channel geometry.

\section{Numerical scheme}

The eqn. (1) through eqn. (3) characterizes as nonlinear hyperbolic partial differential equations and closed form solutions of these equations are not conceivable with the exception of rare simplified cases. Therefore, they are solved by numerical schemes. In this model, a finite difference method is used to solve MacCormack scheme [9]. Two possibility of this scheme are conceivable for one dimensional flow. In one alternate, forward finite differences are used in the predictor part and backward finite differences are used in the corrector part. In the second alternative, backward finite differences are used in the predictor part and forward finite differences are used in the corrector part. The values of the variables so determined during the predictor part are used during the corrector part. The finite difference approximations for the derivatives of a variable ' $\mathrm{f}$ are as follows:

Predictor step:

$$
\begin{aligned}
& \frac{\partial f}{\partial t}=\frac{f_{i}^{*}-f_{i}^{k}}{\Delta t} \\
& \frac{\partial f}{\partial x}=\frac{f_{i+1}^{k}-f_{i}^{k}}{\Delta x}
\end{aligned}
$$

Where, $\mathrm{i}=$ the node in spatial grid, $\mathrm{k}=$ the node in time grid, $\Delta \mathrm{x}=$ the distance step and $\Delta t=$ the time step. An asterisk refers to the predicted values of the variable.

Corrector step:

$$
\begin{aligned}
& \frac{\partial \mathrm{f}}{\partial \mathrm{t}}=\frac{\mathrm{f}_{\mathrm{i}}^{* *}-\mathrm{f}_{\mathrm{i}}^{*}}{\Delta \mathrm{t}} \\
& \frac{\partial \mathrm{f}}{\partial \mathrm{x}}=\frac{\mathrm{f}_{\mathrm{i}}^{*}-\mathrm{f}_{\mathrm{i}+1}^{*}}{\Delta \mathrm{x}}
\end{aligned}
$$


Where, the two asterisks denote the value of the variables calculated in the corrector step.

\section{Boundary conditions}

The above equations determine the values of $\mathrm{h}, \mathrm{q}$, and $\mathrm{z}$ at the new time level $\mathrm{k}+1$ at each interior grid points $(\mathrm{i}=2,3 \ldots \mathrm{N}-1)$. The values at the boundary grid points $(\mathrm{i}=$ and $\mathrm{N})$ cannot be calculated by using these equations. Therefore, they are calculated by using boundary conditions. For one-dimensional flows, characteristic method gives acceptable results and is employed here in. For the proper functioning of the model two boundary conditions at upstream boundary and one boundary condition at downstream end are required. In addition to these, every computational grid needs initial conditions. Uniform unit discharge $\left(\mathrm{q}_{0}\right)$, uniform flow depth $\left(\mathrm{h}_{0}\right)$ and bed levels as calculated from initial bed slope $\left(\mathrm{S}_{0}\right)$ were provided as initial conditions, i.e.,

$$
\begin{aligned}
& \mathrm{q}(\mathrm{x}, 0)=\mathrm{q}_{0} \\
& \mathrm{~h}(\mathrm{x}, 0)=\mathrm{h}_{0} \\
& \mathrm{z}(\mathrm{x}, 0)=\mathrm{z}_{0} \quad \text { for } \mathrm{x}=0
\end{aligned}
$$

The flow depth, $\mathrm{h}$ at node 1 was determined by extrapolation from the already calculated values at the interior nodes using the MacCormack scheme. The downstream boundary condition was the constant depth, which was specified by $h\left(x_{n}, t\right)=h_{0}$ for $t \geq 0$. This was based on the assumption that the channel was long and the bed transients would not reach the downstream end within the period for which conditions were computed and that the variation in flow depth would be negligible. The values at the interior nodes are used for extrapolation to determine to discharge and the bed elevation at the downstream end.

\section{Model Performance Assessment}

The Coding of the model has been checked by comparing it results with the already computed by the implicit model [10] namely, Chen, Chang and Richard and LUM [10]. The results are shown in Figure 3. It indicates that the algorithm performs well and the overall agreement is satisfactory.

Channel section is wide rectangular; the length of the reach, $\mathrm{L}=14$ $\mathrm{km}$; bed slope, $\mathrm{S}_{0}=0.0003$; and Manning's $\mathrm{n}=0.01$.
The value of porosity p was assumed as 0.528 and the sediment load was calculated by using eqn. (5) as given below:

$$
\mathrm{Q}_{\mathrm{s}=0.00385} \frac{\left(\frac{\mathrm{Q}}{\mathrm{A}}\right)^{3}}{\mathrm{~h}} \mathrm{Q}
$$

The inflow hydrograph was defined as a steady flow of $6.2 \mathrm{~m}^{3}$ per second per unit width. The following equation was described by Chen [11] for second upstream boundary condition.

$$
\Delta \mathrm{A}_{\mathrm{d}}(1)=\frac{\Delta \mathrm{t}}{2 \mathrm{p} \Delta \mathrm{x}}\left[\mathrm{Q}_{\mathrm{s}_{2}}^{\mathrm{n}+1}-\mathrm{Q}_{\mathrm{s}_{1}}^{\mathrm{n}+1}+\mathrm{Q}_{\mathrm{s}_{2}}^{\mathrm{n}}-\mathrm{Q}_{\mathrm{s}_{1}}^{\mathrm{n}}\right]
$$

$\mathrm{Q}_{\mathrm{s} 1}$ is the sediment input discharge at the upstream node, $\mathrm{Q}_{\mathrm{s} 2}$ is sediment discharge at node 2 calculated by eqn. (10), $\mathrm{n}$ represent the time step.

The initial flow along the reach was assumed to be $6.2 \mathrm{~m}^{3}$ per second per unit width. The initial upstream and downstream depths used are given at different nodes ranges from 2.15 to 4.0 meters respectively. An assumed constant water stage was defined. The equation used is;

$$
\mathrm{h}_{\mathrm{n}}=4.0-\mathrm{z}_{\mathrm{n}}
$$

$\mathrm{h}_{\mathrm{n}}$ and $\mathrm{z}_{\mathrm{n}}$ are flow depth and total bed elevation change at downstream end of reach since start of simulation, respectively. The sum of $h_{n}$ and $\mathrm{z}_{\mathrm{n}}$ remains constant. Initially $\mathrm{z}_{\mathrm{n}}$ at downstream is zero.

The deviation is anticipated to arise from different steps in linearization, solution methods choose (Implicit and explicit) and handling of insignificant terms in the governing equations. Term concerning for rate of bed level change with time is neglected in the governing equations used in this study while same is explicitly coupled in the governing equations used in the models developed by Ghumman [10]. It might be due to this insignificant term that may become significant at point of maximum deposition. Linearization of friction force, pressure force and convective acceleration terms may also be one reason. Wetted perimeter used for unit width of channel is a valuable variable that affects results.

Lustrous discrepancy trends of convective acceleration, pressure force and friction force terms of momentum equation during normal execution of model are shown in Figure 4. While, tremendous and

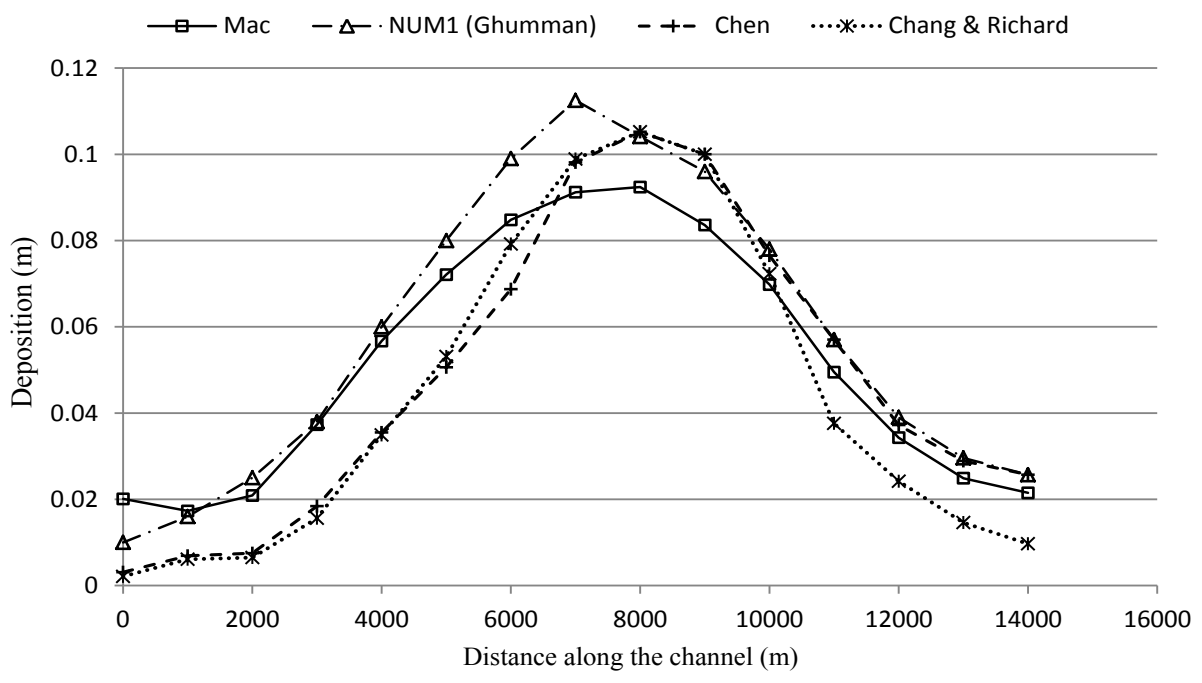

Figure 3: Bed level changes compared with published solution. 
Citation: Riaz MZB, Shakir AS, Masood M (2017) One Dimensional Numerical Simulation of Aggradation-Degradation in a Channel Using Finite Difference Method Case Study Chashma Right Bank Canal (CRBC). Fluid Mech Open Acc 4: 178. doi: 10.4172/2476-2296.1000178

Page 4 of 8

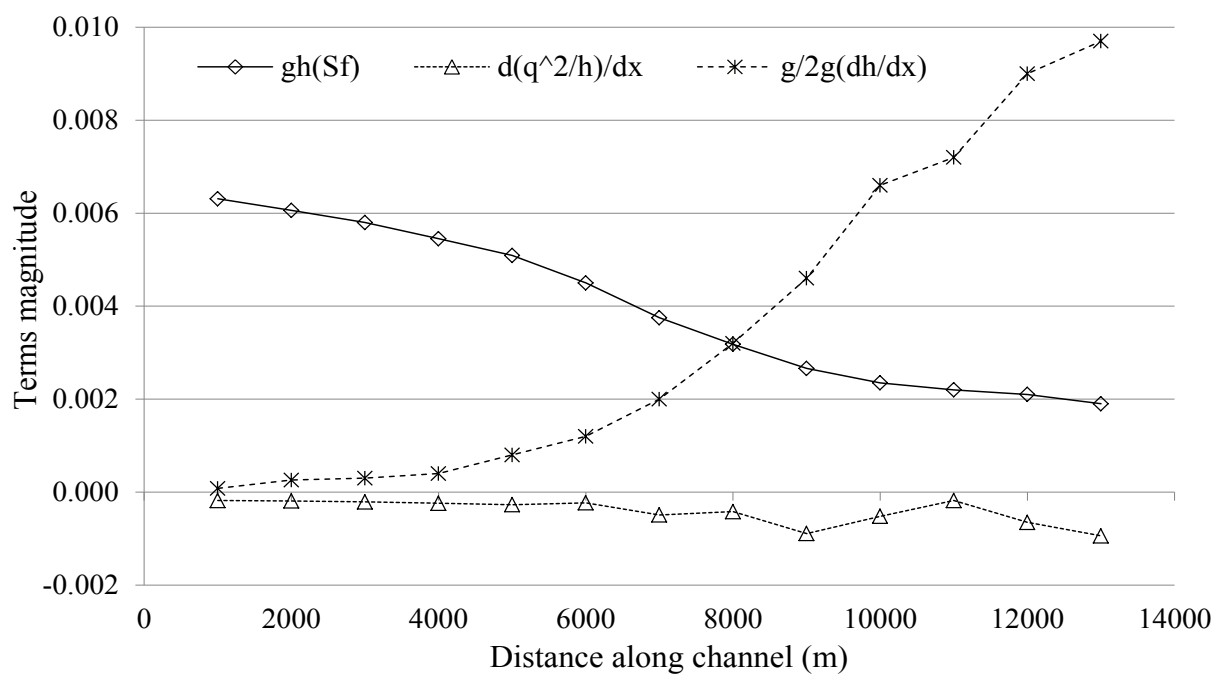

Figure 4: Variation of terms along the channel during normal execution.

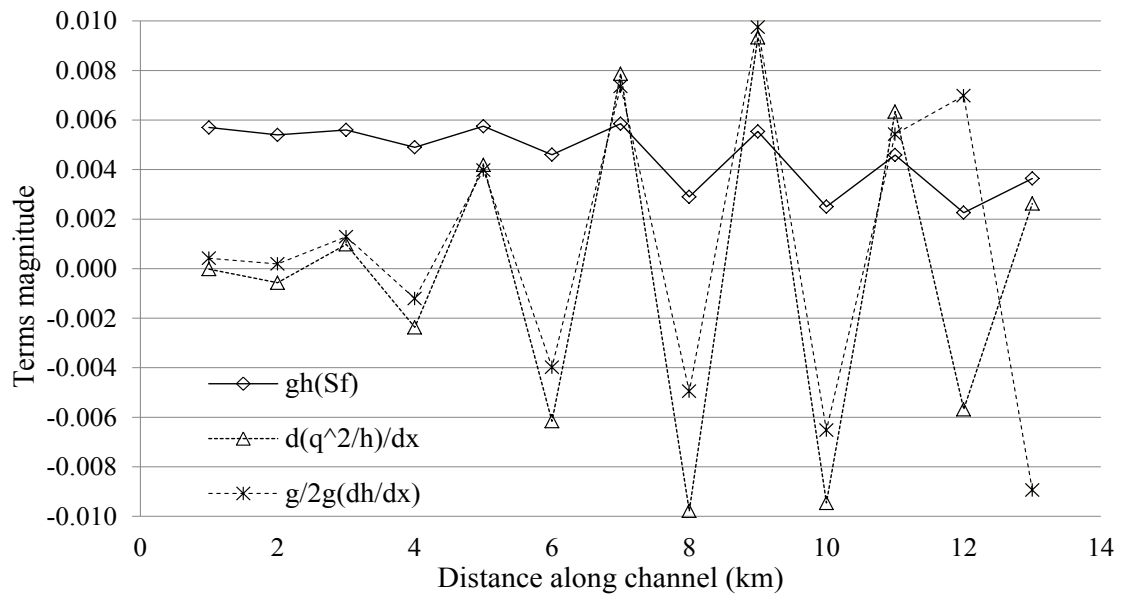

Figure 5: Variation of terms along the channel when execution terminates.

senseless variation of these terms due to the instability when model stops execution is given in Figure 5.

Mostly stability is affected due to hydraulic parameters, physical boundary system and sensitivity to input data e.g. slightly change any of the input parameter and see how it goes. Inappropriate initial conditions also introduce false transients into the simulation which may lead to improper results.

\section{Application to CRB canal}

Chashma Right Bank Irrigation Project (CRBIP) is a large irrigation system spread over two provinces (Punjab and North West Frontier Province) of Pakistan. It is the $1^{\text {st }}$ irrigation system in Pakistan, initially conceived as a crop based supply system, and then followed by the design and construction of its physical infrastructure.

Chashma Right Bank Canal (CRBC) off-takes from Chashma Barrage on right flank of Indus River and runs almost parallel to the river along the highest contour for about $273.5 \mathrm{Km}$ (170 miles). The total command area of the project is 230,675 hectares (570,000 acres) of land on the right flank of River Indus. The canal had been planned to deliver design discharge of 138.3 cumecs ( 4879 cusecs). The distribution system is about $1,100 \mathrm{Km}$ (700 miles) long and 83 secondary channels irrigate a narrow strip of land between the Chashma Right Bank Canal and Indus River.

The first $38 \mathrm{Km}$ ( 24 miles) of the canal are unlined with a slope of 1 in 8,000. A flat slope of 1 in 14,000 has been provided in the next 201 $\mathrm{Km}$ (125 miles). Last $17.7 \mathrm{Km}$ (11 miles) in the tail reach have a steep slope of 1 in 8,000. The general plan and location map shown in Figure 6.

To calibrate and verify the model, these data can be used including water stages and channel bed variations. Field data from 2000, including geometric cross-sectional data and bed material data, are used as the initial condition. Data from 2000 to 2001 were used to calibrate the model and data from 2002 to 2003 were used for verification.

\section{Parameter examination}

The total simulation time was divided into low sediment flow period and high sediment flow period. High sediment flow period was from May to Sept whereas rest of the period being low sediment flow. For the year 2001, measured hydraulic and sediment data can be used to calculate the inflow sediment load. The sediment rating was prepared for the low sediment flow and high sediment flow separately. 


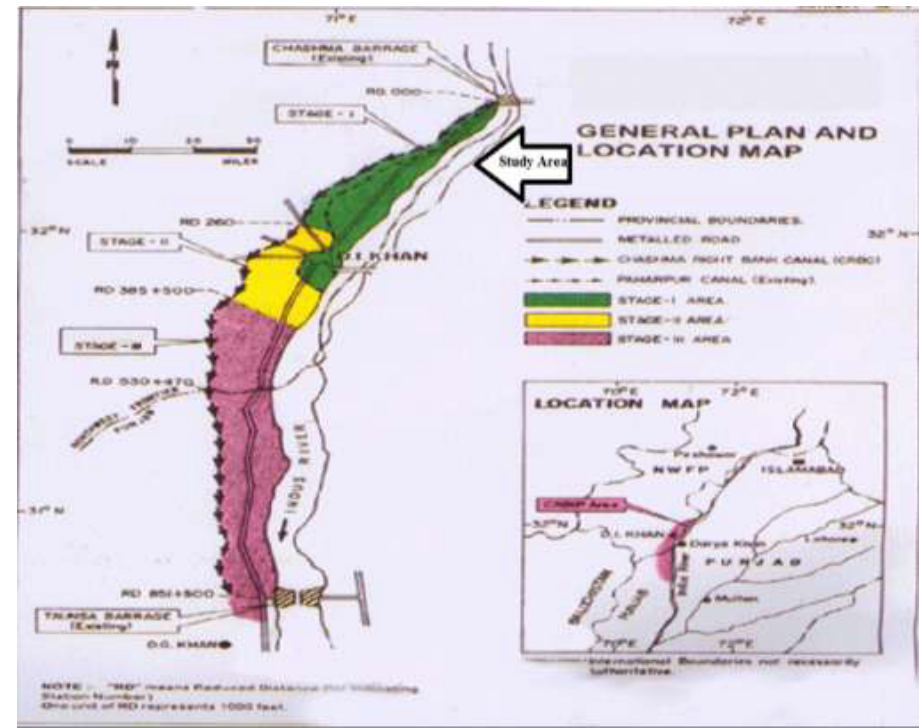

Figure 6: General plan and location map of CRB canal.

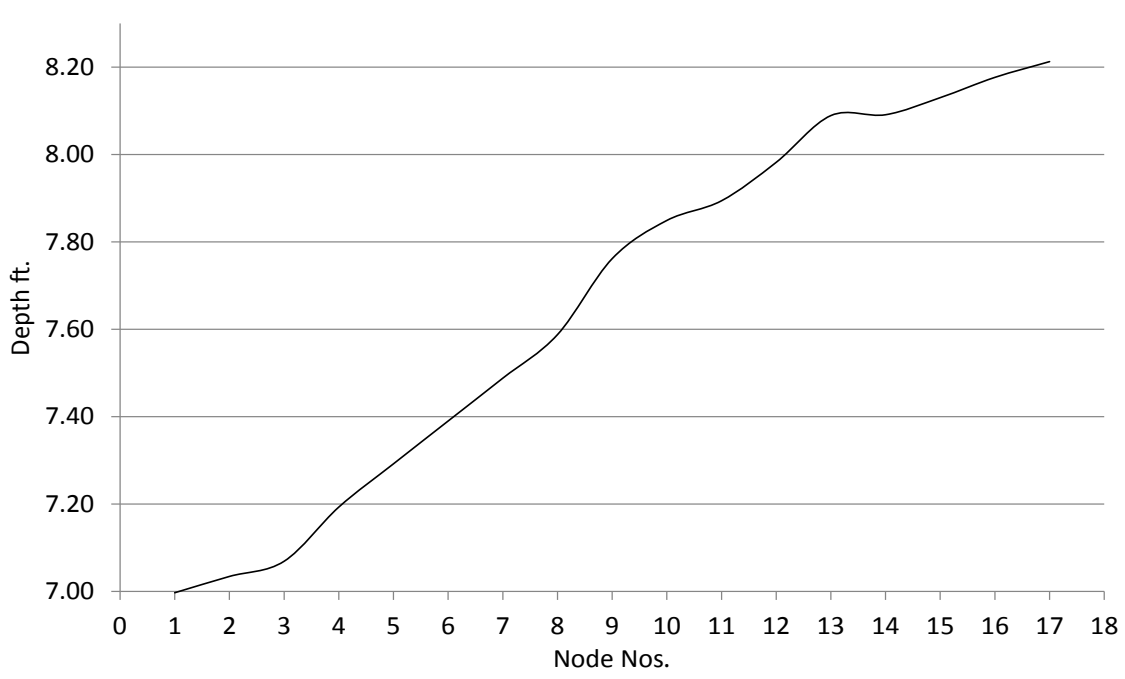

Figure 7: The Initial depths at different node.

Inflow sediment rating used the outflow sediment rating for the next reach and so on.

A single representative cross section was chosen, to avoid an enormous load of calculations. The geometric properties of all the individual sections over the entire reach were averaged for this representative cross-section. The reach length, $\mathrm{L}=15$ mile $(24 \mathrm{~km})$; bed slope, $\mathrm{S}_{0}=0.000125$; Manning's $\mathrm{n}=0.016$

The value of porosity, $\mathrm{p}=0.3$; sediment discharge was calculated using eqn. (5) in which values of empirical constants were taken as; $\alpha=0.00000006 ; \beta=3.248$; frictional slope was estimated by Manning's formula.

The initial depths were assumed as normal depth is calculated by Manning's formula using the assumed cross-section as given below.

$$
\mathrm{A}=(\mathrm{Y}-7.3) / 0.000832
$$

$\mathrm{Pw}=2^{\star} \mathrm{y}+\mathrm{T} ; \mathrm{Pw}$ is wetted perimeter and $\mathrm{T}$
Substituting these terms in the Manning's eqn.;

$$
\mathrm{Q}=\frac{\mathrm{A}}{\mathrm{n}} \cdot\left(\frac{\mathrm{A}}{\mathrm{Pw}}\right)^{2} \cdot \mathrm{S}^{0.5}
$$

The downstream boundary was defined by the Manning's equation in the MacCk. Couple Model

Using the flow depth satisfies the Manning's equation at initial conditions and thus model runs successfully without facing any complication of instability due to Manning's equation during computations. However, model execution is terminated immature if values of initial flow depths other than (Figure 7 )were used.

For $\mathrm{dx}=1000 \mathrm{ft}$;; $\mathrm{dt}=\mathrm{c}^{\star} \mathrm{dt} 1$; Any increase and decrease of $\mathrm{dx}$ and $\mathrm{dt}$ have tremendous effect on stability and execution of model. If $\mathrm{c}=0.75$, it stops only after 48 time steps and for $\mathrm{c}=0.65$ its simulation is completed upto 90 days. Stability problem was overcome by using $\mathrm{c}=0.55$ that simulated for more than 198 days and 10841 time steps when ram quota exceeded with the message "Error during write, Disk 
Citation: Riaz MZB, Shakir AS, Masood M (2017) One Dimensional Numerical Simulation of Aggradation-Degradation in a Channel Using Finite Difference Method Case Study Chashma Right Bank Canal (CRBC). Fluid Mech Open Acc 4: 178. doi: 10.4172/2476-2296.1000178

Page 6 of 8

quota failure" as output file is too large and big. Hence direct display of results was necessary to avoid excess of memory error and for model debugging. However, unnecessary output data could be avoided through managed output file.

The difference between calculated and observed bed level changes is $\pm 0.82 \mathrm{ft}$. It is due to the limitations of the model.

The bed profile computed with the model after simulation was compared with the measured bed profile. The computed and measured bed profiles are well matching with each other as shown in Figure 8.

The sediment deposition pattern depends upon the sediment inflow, hydraulic discharge, flow velocity, roughness, bed slope and bed material gradation. The sediment deposition pattern was estimated by plotting the change in bed elevation at different time intervals. The Changes in bed elevation at different time interval are plotted in Figure 9.

\section{Verification}

Using the parameters determined in the previous analysis, the model is applied to simulate the channel bed evolutions of CRB canal from 2002 to 2003 . The total simulation period is 330 days. The comparisons of the observed and computed bed profile and bed change are shown in (Figures 10 and 11) respectively. The overall accuracy is good. The computed and measured bed profiles are well matching with each other as shown in (Figure 10).

The deposited sediment resulted in raising the bed of the canal at different locations. The graph was plotted for bed changes and it is shown (Figure 11).

Running MacCk. Couple Model with this data is humble effort of this study. Generally set trends of results are fairly responsive but need further minute model calibration and refinement which is expected

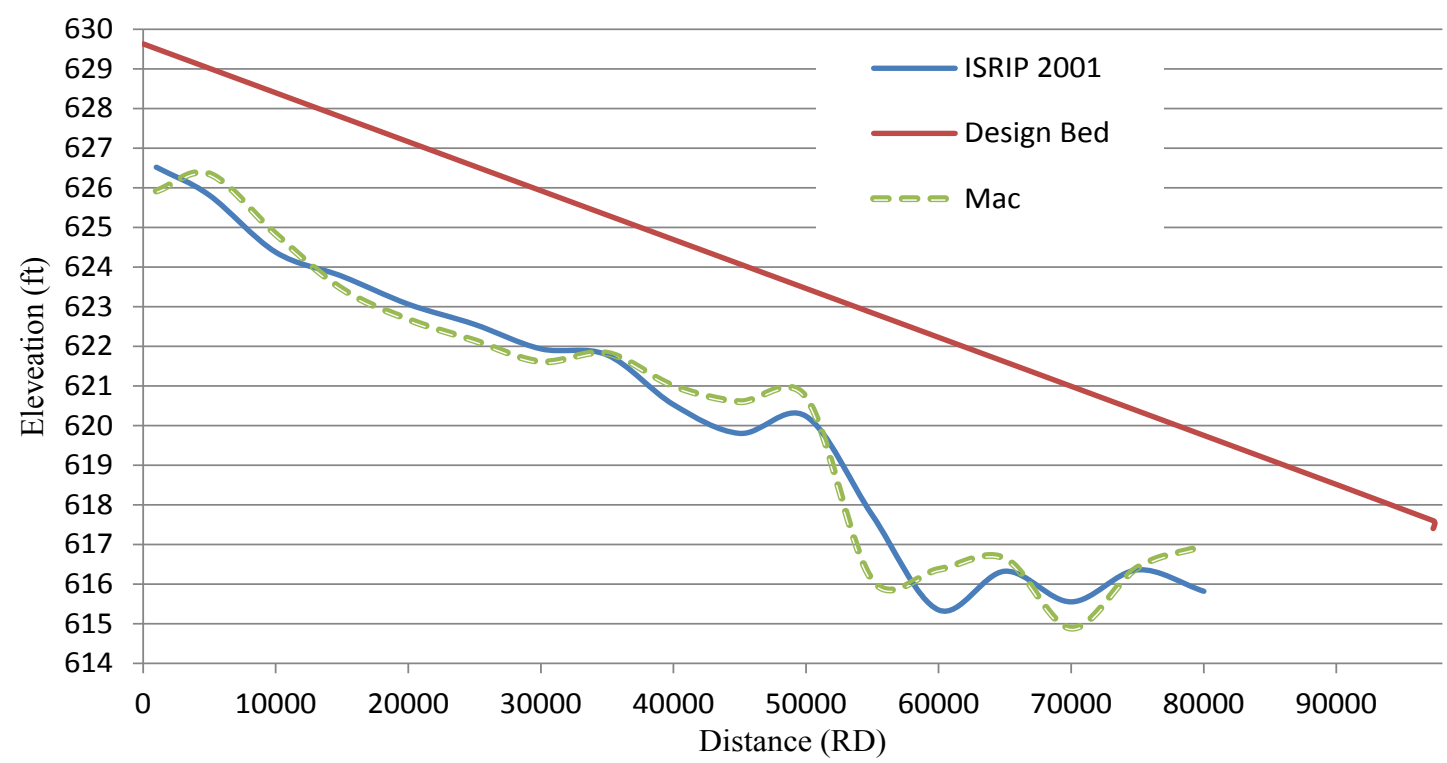

Figure 8: Observed and computed bed profile after 325 days simulation.

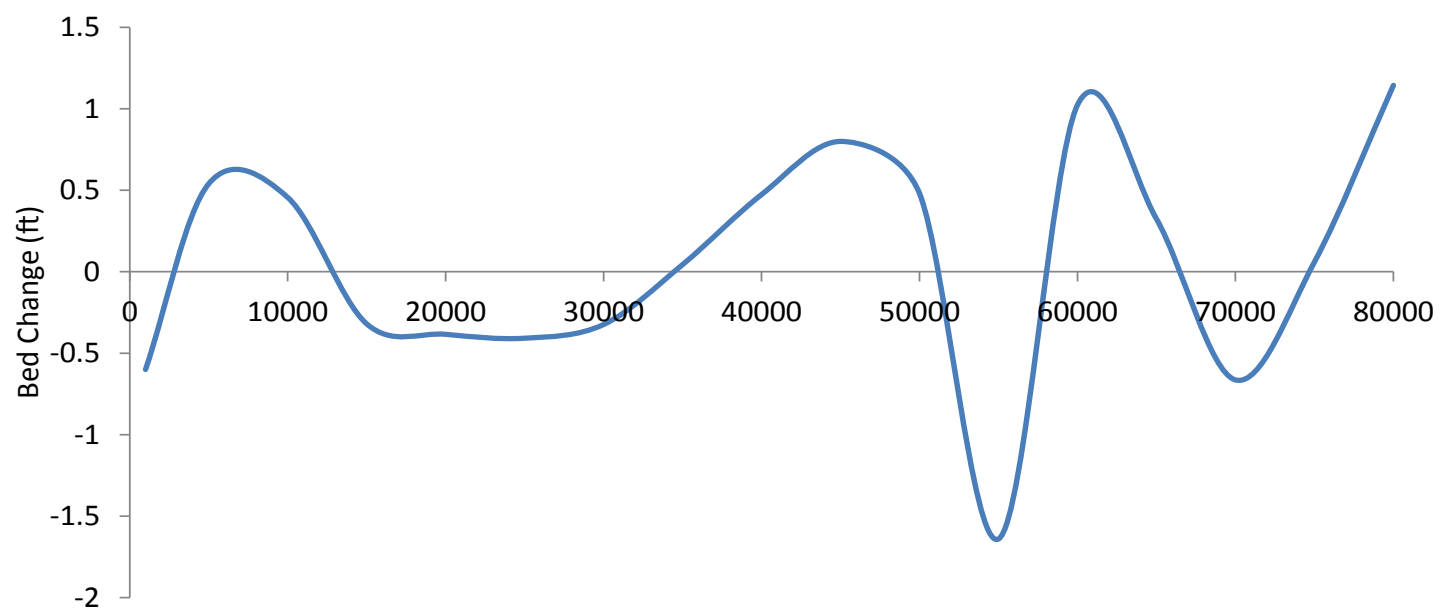

Distance (RD)

Figure 9: Bed change after simulation. 
Citation: Riaz MZB, Shakir AS, Masood M (2017) One Dimensional Numerical Simulation of Aggradation-Degradation in a Channel Using Finite Difference Method Case Study Chashma Right Bank Canal (CRBC). Fluid Mech Open Acc 4: 178. doi: 10.4172/2476-2296.1000178

Page 7 of 8

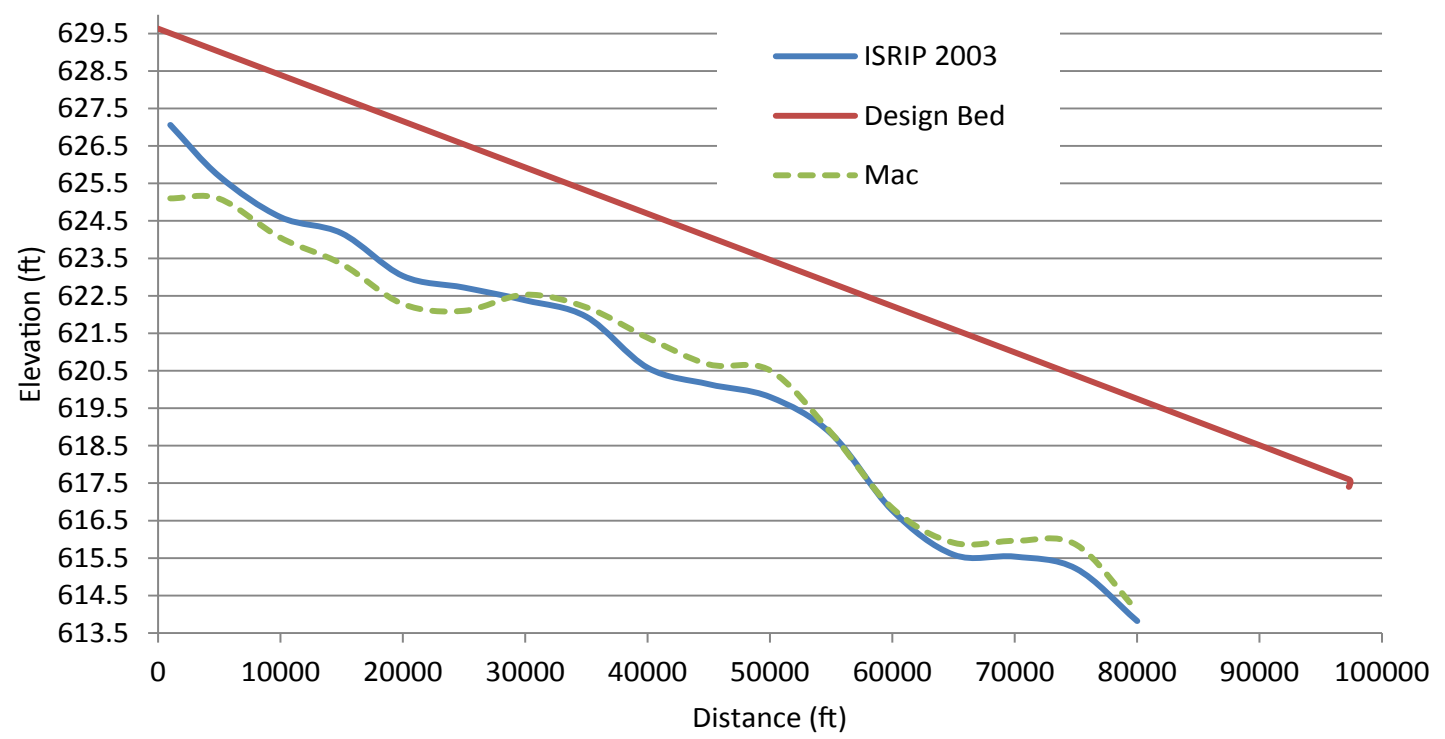

Figure 10: Observed and computed bed profile after 330 days simulation.

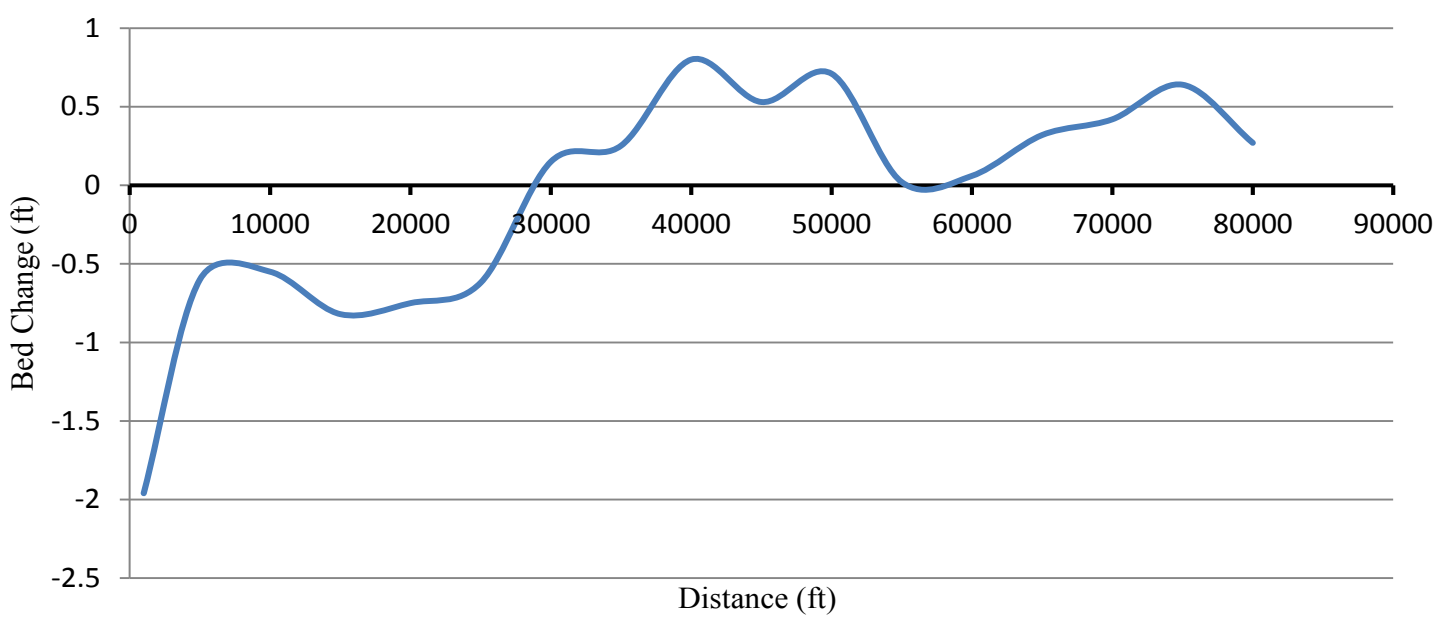

Figure 11: Sediment deposited and bed changes after 330 days.

in future research to make the model a generalized one and viable for sediment as well as for hydraulic routing.

\section{Conclusions}

In this study the change in bed level of channel is studied with application of a one-dimensional mathematical model based on MacCormack scheme. The following conclusions can be made after summarizing the present study:

1- Model developed in this study has fairly good qualitative and quantitative accuracy when applied within the limitations of the model. However, quantitative estimates may be demoralized sometimes.

2- $\quad$ Results and model execution was more stable and flourish for relatively smaller computational time intervals.

3- By using different equations for similar conditions will yield transport rates that might differ by several order of magnitude. Therefore, it is difficult to reach at a universal transport equation.
4- The MacCormack scheme can be applied to develop a twodimensional model to study the two-dimensional problems and also a three-dimensional model to study three-dimensional problem.

\section{References}

1. Begin ZB (1981) Development of longitudinal profiles of alluvial channels in response to base level lowering. Earth Surface Processes and Land Forms 6: $46-68$.

2. Soni JP, Garde RJ, Raju KGR (1980) Aggradation in streams due to overloading. Journal of the Hydraulics Division ASCE 106: 117-132.

3. Yen CL, Chang SY, Lee HY (1989) Recovery of channel bed in aggradationdegradation process. Proceedings, 23rd congress of IAHR, Ottawa, Canada 323-329.

4. Yen, CL, Chang SY, Lee HY (1992) Aggradation-degradation process in alluvial channels. Journal of Hydraulic Engineering, ASCE 118: 1651-1669.

5. Alam M (1998) Application of MacCormack scheme to the study of aggradation degradation in alluvial channels M.Sc. Engineering thesis work, Department of Water Resources Engineering, BUET, Dhaka. 
Citation: Riaz MZB, Shakir AS, Masood M (2017) One Dimensional Numerical Simulation of Aggradation-Degradation in a Channel Using Finite Difference Method Case Study Chashma Right Bank Canal (CRBC). Fluid Mech Open Acc 4: 178. doi: 10.4172/2476-2296.1000178

Page 8 of 8

6. Kassem AA, Chaudhry MH (2002) Numerical Modeling of Bed Evolution in Channel Bends. Journal of Hydraulic Engineering, ASCE 128: 507-514.

7. Deng J, Li Y (2003) A study on the equilibrium profile for the Luoshan-Hankou reach in the middle Yangtze river. International Journal of Sediment Research 18: $107-114$

8. DHI Inc (2003) 301 South State Street, Newtown, PA, 18940, USA.

9. MacCormack R (1969) The effect of viscosity in hypervelocity impact cratering
Paper 69 354, American Institute of Aeronautics and Astronautics, Cincinnati, Ohio.

10. Ghumman AR (1994) The development and optimization of numerical models for the sediment routing in rivers. Ph.D thesis. Queen Marry and Westfield College, University of Landon.

11. Chen WY, Stegen GR (1974) Experiments with maximum entropy power spectra of sinusoids. Journal of Geophysical Research, $79: 3019-3022$. 